\title{
Effects of Xiang Sha Yang Wei Wan on Ethanol-Induced Gastric Ulcer in Sprague Dawley Rats: a Histological Study
}

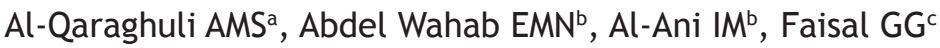

\author{
a Division of Basic Medical Sciences, Faculty of Medicine, Cyberjaya University College of Medical Sciences, \\ Cyberjaya, Selangor, Malaysia. \\ ${ }^{b}$ Department of Basic Medical Sciences, Kulliyyah of Medicine, International Islamic University Malaysia, \\ Kuantan, Pahang, Malaysia. \\ c Department of Basic Medical Sciences, Kulliyyah of Dentistry, International Islamic University Malaysia, \\ Kuantan, Pahang, Malaysia.
}

\begin{abstract}
Introduction: Xiang Sha Yang Wei Wan (XSYWW) is a Chinese traditional medicine that is used for gastrointestinal disorders, specifically gastric ulcer in many countries of South-East Asia. The aim of the study was to evaluate the potential effects of XSYWW on ethanol-induced gastric ulcer in rats by means of histological Study. On a similar basis of treatment, ranitidine, a conventional medication was used as gold standard. Methods: Fifty five male Sprague-Dawley rats (250-300 gm) were divided into four groups. Group I (ethanol treated group) was the control group and gastric ulcers were induced by administering $100 \%$ ethanol (1 ml/200 g). Group II (Pre-treatment group) was divided into two subgroups; they were orally fed with $1.0 \mathrm{gm} / \mathrm{kg}$ and $2.0 \mathrm{gm} / \mathrm{kg}$ respectively of XSYWW solution. Thirty minutes later they were administered with absolute ethanol as in group I. Group III, was given an oral dose of $2 \mathrm{gm} / \mathrm{kg}$ of XSYWW solution after one hour of ethanol administration. Group IV was given an oral dose of $200 \mathrm{mg} / \mathrm{kg}$ ranitidine solution after one hour of ethanol administration. Five rats from groups I, III and IV were sacrificed on day 1, 2 and 3 while the animals of group II were sacrificed one hour after ethanol administration. Results: Histological study of the stomachs from ethanol treated rats showed multiple ulcers of various depths that reached the muscularis and the serosa. Conclusion: Pre or post-treated rats with XSYWW showed that XSYWW has protective effect against ethanol-induced gastric mucosal lesion. However, there was a faster and more complete healing process in the ranitidine treated group when compared to the XSYWW treated subjects.
\end{abstract}

KEYWORDS: Ethanol, gastric ulcer, ranitidine, Xiang Sha Yang Wei Wan (XSYWW), traditional medicine.

\section{INTRODUCTION}

Peptic ulcers are defects in the gastrointestinal mucosa that extend through the muscularis mucosae. Peptic ulcer includes both gastric and duodenal ulcers and has been considered as a major threat to the world's population over the past two centuries, with a high morbidity and substantial mortality. ${ }^{1}$ Gastric ulcers development occurs with acid and breakdown of mucosal defence. ${ }^{2}$

Uncontrolled acid secretion and ulceration of the gastric mucosa due to several reasons have posed serious problems to the human health all over the world. ${ }^{3}$

Corresponding author:

Professor Imad M. Al-Ani,

Department of Basic Medical Sciences,

Kulliyyah of Medicine,

International Islamic University Malaysia,

P.O. Box 141, 25710 Kuantan, Pahang, MALAYSIA.

Tel. +60179776014

E-Mail: imad_alani@yahoo.com
Epidemiological data for this disease, and its complications have shown striking geographical variations in incidence and prevalence. The overall prevalence is highly variable in relation to geography, ethnicity, age, and socioeconomic factors; high in developing countries and lower in the developed world. ${ }^{4}$ Peptic ulcers are more common among Chinese and Indians when compared with Malays in both Malaysia ${ }^{5}$ and Singapore. ${ }^{6}$ In India, peptic ulcer is more prevalent in Jammu and Kasmir, followed by Southern India and North India. ${ }^{7}$ The prevalence of peptic ulcer disease in the United States is approximately $12 \%$ in men, and $10 \%$ in women. ${ }^{8}$

It is now accepted that gastric lesions are caused by an imbalance between acid and pepsin secretion, and defensive factors such as bicarbonate secretion and gastric mucosal barrier. ${ }^{9}$ A wide variety of clinical disorders and gastric damage is caused by physical, chemical and psychological factors that lead to gastric ulceration in human and experimental animals. ${ }^{10}$ Most peptic ulcers developed as a result of chronic alcoholism, ${ }^{11}$ the use of antirheumatic medicine, (NSAIDS or aspirin) and the most common cause is the persistent infection of the stomach by the 
"Helicobacter pylori" bacteria. ${ }^{12}$ The development of ethanol-induced gastric ulcer is of multifactorial origin with the decrease in the amount of gastric mucus associated with significant production of free radicals leading to increased lipid peroxidation which in turn induces damage to cell and cell membranes..$^{13}$ In addition to the direct mucosa damage, the abuse of alcohol is also associated with development of gastric diseases such as gastritis and even gastric cancer. ${ }^{14}$

Several pharmaceutical products have been used for the treatment of peptic ulcer such as proton pump inhibitors, H2-blockers, anti $H$. pylori drugs, etc. Although these drugs have developed remarkable progress in ulcer therapy, such as decreasing mortality and morbidity rates, efficacy is still debatable. These drugs have many adverse effects, including gastrophy, ${ }^{15}$ diarrhoea, ${ }^{16}$ impotence, chlorhydria, hypergastrinemia and hyperplasia of enterochromaffin-like cells. ${ }^{17}$ Due to the side effects that developed during and after treatment, many herbal medicines have been recommended for the treatment of peptic ulcer. Herbal drugs are prescribed widely as an alternative treatment to available synthetic drugs for treatment of ulcer possibly due to lower costs, availability, fewer adverse effects and perceived effectiveness. ${ }^{18}$ According to the World Health Organization (WHO), almost $65 \%$ of the world's population has incorporated medicinal agents into their primary modality of health care. ${ }^{19}$

The people in Malaysia (especially, the Chinese) suffering from gastrointestinal problems used a traditional herbal medicine, the Xiang Sha Yang Wei Wan (XSYWW). It is also used as traditional medicine in many of the South-East Asian countries. XSYWW is a mixture of thirteen components, namely; Tangerine Peel (Pericarpium Citri Reticulatai) [10\%], Poria (Poriae Cocos) [10\%], White Atractylodes (Rhizoma Atractilodyis Macrocephalae) [10\%], Pinelliae Tuber (Rhizoma PinelliaePreparatum) [10\%], Licorice Root (Radix Glyeyrrhizae) [10\%], Aplotaxsis Auriculata (Radix Auklandiae) [7\%], Amomum Seed (Fructus Amomi) [7\%], Nut Grass Rhizoma (Rhizoma Cyperi) [7\%], Round Cardamon Fruit extract (Fructus Amomi Rotundus) [7\%], Immature bitter orange (Fructus Aurantii Immaturus) [7\%] Agastache (Herba Pogastemonis) [7\%], Ziziphusjujuba Mill or chinese date (Fructus Jujubae) [5\%] and Ginger (Rhizoma Zingiberis Recens) [3\%]. To the authors' knowledge, there has been no published scientific report available in the literature in support of the traditional medical claims of XSYWW. The objectives of this study were to investigate anti-gastric ulcer healing actions of the XSYWW in ethanol-induced gastric mucosal damage in rats.

\section{MATERIALS AND METHODS}

\section{Drugs preparation}

For the experimental purpose, XSYWW (Lanzhou Foci
Pharmaceutical Ltd, LANZHOU, CHINA) and ranitidine (Salutas Pharma GmbH, BARLEBEN, GERMANY) were ground separately, dissolved in normal saline, homogenised using a magnetic stirrer to get a homogenous solution. The homogenised solution of the XSYWW yielded $2 \mathrm{gm} / \mathrm{kg}$, while the homogenised solution of the ranitidine yielded $200 \mathrm{mg} / \mathrm{kg}$.

\section{Animals and experimental design}

Fifty five healthy adult Sprague Dawley male rats weighing 250-350 g were used in this study. They were housed (in triplets) in polypropylene cages under standard laboratory conditions. The rats received pellets and were allowed free access to water during the experiment, and they were kept under controlled 12-hour light-dark cycle. The animals were treated according to the Standards and Regulations for the Care and Use of Laboratory Animals of the National Institutes of the Health and according to the guidelines of IIUM animal ethics. Prior to the experiment, the animals were starved for twenty-four hours with a free access to water.

The animals were divided into four groups of fifteen animals each; except (for group II which contained ten). Group I was ethanol treated group considered as the control group, in which gastric ulcers were induced by administering $100 \%$ ethanol ( $1 \mathrm{ml} / 200 \mathrm{~g}$, intragastric) on the second day of starvation using an oral feeding stainless steel 20G, 1.5-inch needle. Group II (pretreatment group) was divided into two subgroups (of five rats each), and they were orally fed with $1.0 \mathrm{gm} /$ $\mathrm{kg}$ and $2.0 \mathrm{gm} / \mathrm{kg}$ respectively of XSYWW solution and 30 minutes later they received absolute ethanol as in group I. Group III was given an oral dose of $2 \mathrm{gm} / \mathrm{kg}$ of XSYWW solution after one hour of ethanol administration. Group IV (Ranitidine Group) was given an oral dose of $200 \mathrm{mg} / \mathrm{kg}$ of Ranitidine solution after one hour of ethanol administration. Five rats from groups I, III and IV were sacrificed on day 1, 2 and 3 while the animals of group II were sacrificed one hour after ethanol administration.

The stomachs were removed via a mid-sagittal incision, thoroughly washed in normal saline and opened along their greater curvature. Small portions of each stomach from the greater curvature were fixed in 10\% neutral buffered formalin, dehydrated by graded series of ethanol, cleared in xylene, impregnated and embedded in paraffin wax. Paraffin sections of $5 \mu \mathrm{m}$ thick were stained with Haematoxylin and Eosin ( $\mathrm{H} \& \mathrm{E})$ ) and periodic acid Schiff (PAS).

In this study, the ulcerated area included all damages of the gastric mucosa which penetrates the muscularis externa. Therefore, the lesions were nominated depending on the layers involved; 'shallow' ulcer erosion that involves only the lining epithelium, 'medium' sized ulcer that extends into the mucosa and 'deep' ulcer which extend deep involving the submucosa and the muscularis externa. 


\section{RESULTS}

\section{Group I (Ethanol Group)}

Ethanol treated rats sacrificed on day one showed multiple ulcers of various depths that reached the muscularis and the serosa (Fig. 1A). Rats sacrificed on day two showed the same outcome of multiple deep ulcers that extended to the deep layers (Fig. 1B). Multiple deep ulcers with no evidence of healing were also seen in rats sacrificed on the third day of alcohol treatment (Fig. 1C).
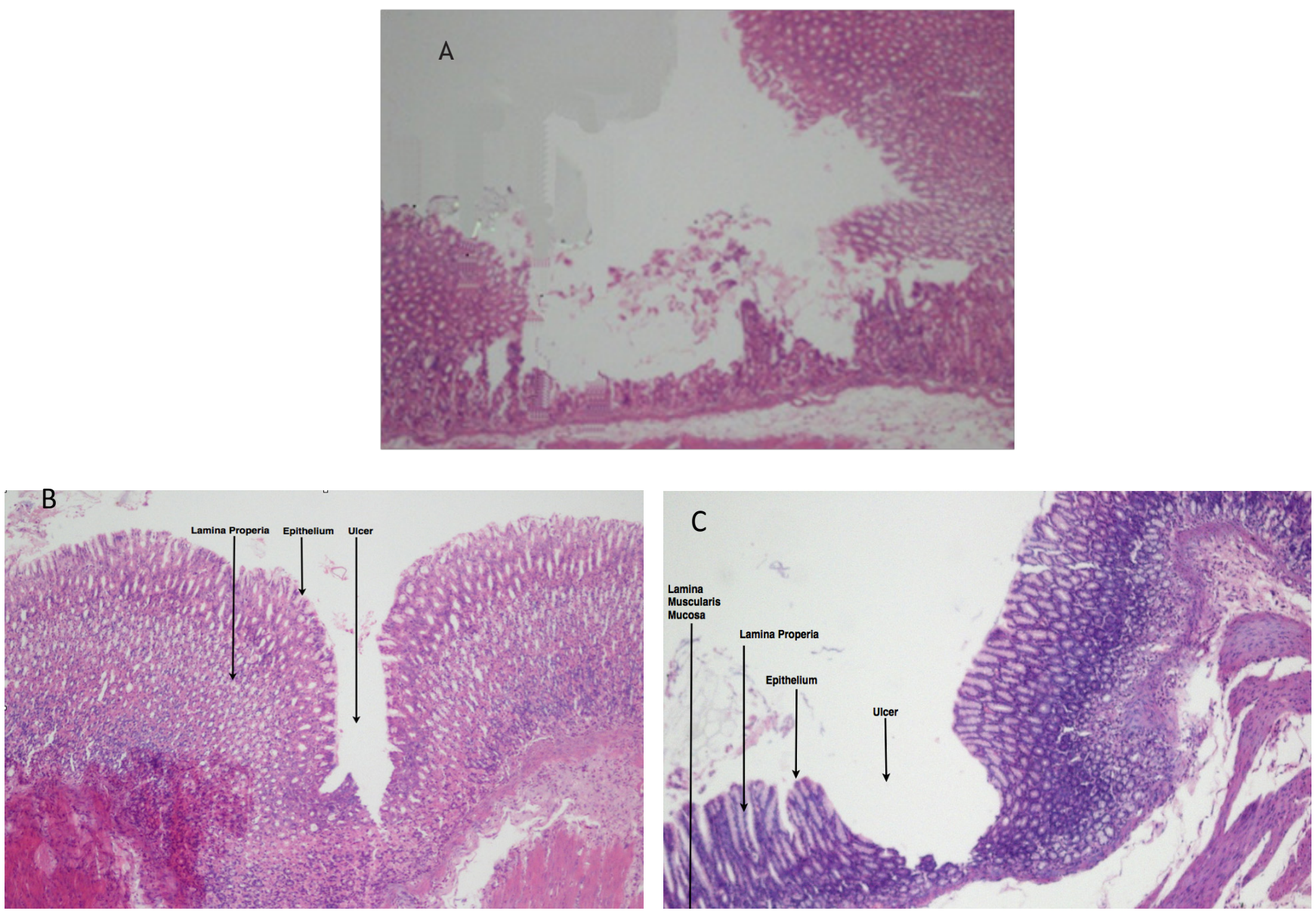

Figure 1.Photomicrographs from Group I (Ethanol treated rats) showing deep gastric ulcers. A; sacrificed on day one, B;sacrificed on day two, C; sacrificed on day three. H\&E. original magnification $\mathrm{X} 10$

\section{Group II (Pre-treatment Group)}

Pre-treatment rat group with 1 -gm/kg XSYWW showed multiple shallow ulcers; however, formation of new capillaries surrounding the lesions with development of flat cells forming epithelial bridges filling some of the tissue gaps was observed (Figs. 2 A \& B). The
$2 \mathrm{mg} / \mathrm{kg}$ dosage group showed ulcers of less severity than the $1 \mathrm{gm} / \mathrm{kg}$ group. The observed changes, ranged from small shallow ulcers to epithelial erosions, were detected in the pre-treatment group of $2-\mathrm{gm} / \mathrm{kg}$ dosage (Figs. 2 C \& D). 

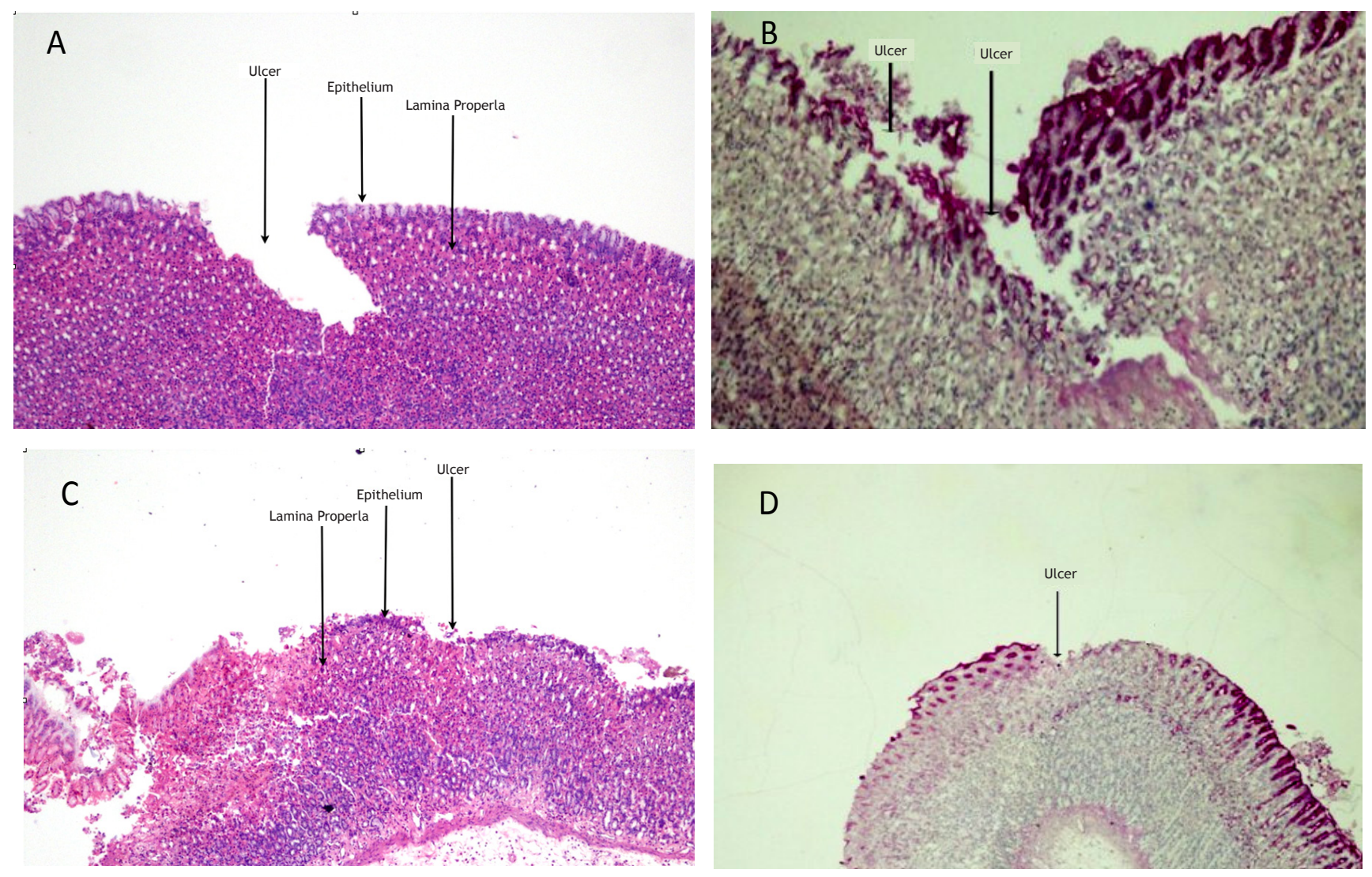

Figure 2. Photomicrographs fromGroup II. A\&B; (Pre-treatment rats with 1-gm/kg XSYWW) showing multiple shallow ulcers with formation of new capillary blood vessels surrounding the lesions, C\&D; (Pre-treatment rats with 2-gm/kg XSYWW) showing less ulcers severity with smaller shallow lesions. A, C \&D (H\&E), B (PAS). Original magnification $\mathrm{X} 10$.

\section{Group III (Post-treatment Group)}

Rats treated with $2 \mathrm{gm} / \mathrm{kg}$ of XSYWW solution (sacrificed on day one) showed multiple deep or medium-size ulcers. However, epithelial bridge formation surrounding these ulcerative regions filled the ulcerative areas, indicating an increase in the cellular regeneration (Fig. 3A). Signs of improvement were detected on the 2nd day indicated by the decrease in medium-sized ulcers. Epithelial growth was pronounced; ulcer beds were shallower due to the deposition of new basement membrane associated with new epithelial cell regeneration and formation of granulation tissue (Figs. 3B \& C). On the 3rd day, most of the sections showed normal mucosa; however, a few shallow ulcers were observed; there was a great regression in the lesion or the coverage of the whole defective area with epithelial cells and new basement membrane with the proliferation of capillaries and fibroblasts in the lamina propria (Fig. 3D). 

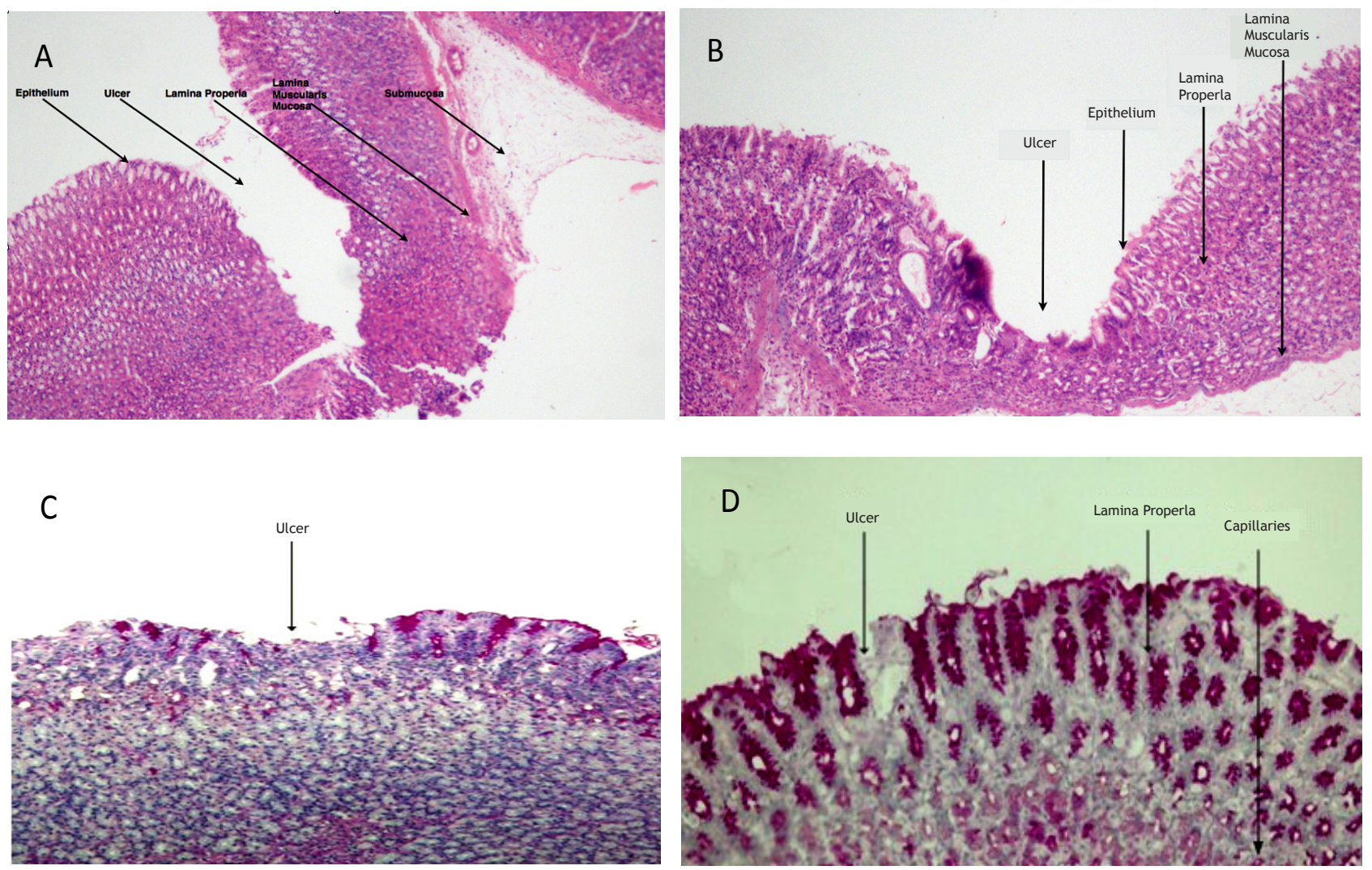

Figure 3. Photomicrographs fromGroup III. (Post-treatment rats with 2-gm/kg XSYWW) A; sacrificed at the 1st day showing multiple deep to medium size ulcers with cellular regeneration by the formation of epithelial tongue, B, C; sacrificed 2nd day showing signs of improvement, of the ulcer bed associated with new epithelial cell regeneration, D; sacrificed at the 3ed day showingnormal mucosa, with one small erosion with proliferation of capillary vessels and fibroblast in the lamina propria. A, B (H\&E), B, C (PAS). Original magnification X10.

\section{Group IV (Ranitidine Group)}

Rats treated with $200 \mathrm{mg} / \mathrm{kg}$ of Ranitidine (after one hour of ethanol administration) sacrificed on day one showed that the gastric wall was moderately affected by having multiple superficial ulcers or few medium-sized ulcers that do not reach deep into the gastric layers. Increase in the vascular proliferation activities in the areas surrounding the lesion were detected (Fig. 4A).

On 2nd day the animals showed shallow ulcers up to complete mucosal healing in several samples.

There was a massive decrease in the size of the defective gaps in the mucosal epithelium and the formation of pithelial bridges that extend from the edge of the lesion (Fig. 4B).

On the 3rd day; most of the specimens were totally healed with no trace or minor evidence of break in the mucosa. Basement membranes were continuous, capillaries proliferations and granulation tissues in the lamina propria were seen (Figs. 4C \& D). 


\section{DISCUSSION}

Peptic ulcer is a distinctive form of ulceration which develops in the stomach when exposed to excessive gastric secretion. ${ }^{20}$ Ethanol-induced gastric ulcers have been widely used for the experimental evaluation of anti-ulcer activities; this method of inducing gastric lesions is a rapid and convenient way of screening plant extracts as anti-ulcer potency. ${ }^{21}$ The present histopathological result of ethanol-induced gastric ulcer is similar to previous studies of ethanol-induced gastric mucosal injury. ${ }^{21,22,23}$ Absolute ethanol is highly corrosive to the gastric mucosa and its mechanism of action on rat gastric mucosa involves superficial necrosis of gastric mucosa and release of histamine and leukotriene $\mathrm{C} 4$ as tissue-derived mediators; ${ }^{23}$ it has a dissolving effect on the gastric mucosa and tends to lower the level of tissue proteins, which in turn lead to decrease the gastric blood flow that result in necrosis. ${ }^{24}$ Ethanol induces gastric ulcer directly; it causes protein precipitant that lead to necrosis of the superficial mucosal cells, ${ }^{25}$ and as a lipid solvent disrupts the plasma membrane of mucosal cells. ${ }^{24}$ It also induces gastric ulcer indirectly by stimulating several mediators of mast or blood cells. ${ }^{24}$ The histopathological changes induced by ethanol can be prevented or reduced by preventing or hampering the release of mediators that cause further injuries or inhibiting them. ${ }^{22,26}$

All of XSYWW herbal components are well known to the Chinese traditional medicine and are very widely used among Asians. ${ }^{27}$ The regeneration process observed in the present investigation is in agreement with earlier data using different medicinal plants such as Opuntiaficusindica ${ }^{28}$ and Falcaria vulgaris. ${ }^{29}$ The presented study has demonstrated that pre-treatment with XSYWW protected the gastric mucosa from ulcer induction by absolute ethanol, and the protection of the gastric mucosa was morphologically improved when the doses were increased. Galati et al. ${ }^{28}$ showed that treatment with Opuntiaficusindica cladodes stimulates a protective response from the gastric mucosa which prevents the development of ethanolinduced ulcers (preventive treatment). The posttreatment of ethanol-treated rats showed progressive healing of the gastric mucosa. The obtained results suggest that XSYWW accelerate the healing process by improving the regeneration rate of the neck cells of the damaged mucosal surface or by rapid migration and deposition of cells in the ulcer bed that had been sloughed from its lining, the improved epithelial tissues were associated with presence of fibroblasts in the lamina propria. The present study also recorded that treatment with ranitidine decreases the lesion parameter in gastric ulcer induced by ethanol in rats. In addition to its inhibitory effect on acid secretion, the efficacy of ranitidine in ulcer healing has been related to the increase cytoprotective activity possibly by enhancing prostaglandins level. ${ }^{30}$

There are various proposed mechanisms by which the administrated medication could help to increase the mucus production and mucous cells. Nakamura et al, ${ }^{31}$ studied the healing of the damaged gastric mucosa induced by ethanol- treatment with aqueous solution of lansoprazole. They observed an increase in myofibroblasts and in fibroblast growth factor, suggesting an involvement of these cells in ulcer healing. The repair of ulcer damage requires a complete reestablishment of the connective tissue of the mucosa, the underlying submucosa, the re-formation of glandular architecture, and the growth of new blood vessels. Angiogenesis is stimulated by means of a variety of growth factors, many of which are secreted by neutrophils, mast cells, and fibroblasts within the granulation tissue. ${ }^{32}$ Galati et al, ${ }^{28}$ studied the cytoprotective effects of Opuntia Ficus on the experimental ethanol-induced ulcers in rats and observed an increase in the number of secretory cells associated with more mucus production; they also suggested that the gastric fibroblasts was involved in the anti ulcer activity.

Das et al., ${ }^{33}$ showed that the world's hottest chilli "Capsicum frutescenes" has an ulcer protective activity similar to that ranitidine on aspirin induced gastric ulcer in albino rats by decreasing acid pepsin and increasing mucus secretion. Khalil et al., ${ }^{3}$ studied the healing effects of Nigella sativa in experimentally aspirin-produced gastric ulcers with comparison to cimetidine and concluded that Nigella sativa is equally effective in healing of gastric ulcer as is cimitidine. The present study reveals that the ethanol-induced gastric ulcer can be healed by using XSYWW to restore a healthy gastric wall in most of the cases within a short time compared to a non medicated; however, the healing results are not as impressive as those obtained by treating the subject with ranitidine. However, higher doses or longer time of treatment with XSYWW may lead to better healing improvement.

The protective and preventive changes in biochemical indices induced by herbal drugs have been studied by many investigators. Coșkun et al., ${ }^{34}$ examined anti-ulcerogen and antioxidant effects of quercetin on ethanol-induced gastric lesions in rats; they found that quercetin significantly reduced ethanol-induced gastric damage and malondialdehyde levels, and significantly increased antioxidant enzyme activities. Darbar ${ }^{35}$ demonstrated that poly herbal formulation 'Livina' significantly decreased the ulcer index and reduction of acid volume, free acidity, and total acidity and increasing rate of $\mathrm{pH}$ in ethanol induced gastric ulcer in a mice model. Chaturvedi et al., ${ }^{36}$ studied the effect of Eugenia jambolana seeds against gastric ulcers induced by cold restraint stress, aspirin, ethanol and pylorus ligation in rats. They found a reduction in ulcer indices, decreased acid-pepsin secretion, enhanced mucin and mucosal glycoprotein and decreased cell shedding.

Ligha and Fawehinmi, ${ }^{37}$ treated their experimental animals with liquorice seed extracts prior to alcohol gastric mucosa damage induction and found that liquorice pre-treatment showed protection against alcohol mucosa damage and significant reduction in alkaline phosphatase and lipid peroxidation product 
which is an index of lipid peroxidation that increased with the ethanol effect. Further biochemical studies are required to study the effect of treatment of gastric ulcer by XSYWW on the biochemical indices and to isolate the active principals and to elucidate the exact mechanism of anti-ulcerogenic activity of XSYWW.

\section{CONCLUSION}

Pre or post-treated rats with XSYWW showed that XSYWW has protective effect against ethanol-induced gastric mucosal lesion. However, there was a faster and more complete healing process in the ranitidine treated group when compared to the XSYWW treated subjects.

\section{REFERENCES}

1. Malfertheiner P, Megraud F, O'Morain C, et al. Current concepts in the management of Helicobacter pylori infection: The Maastricht III Consensus Report. Gut 2007; 56:772-81.

2. Bhave AL, Bhatt JD, Hemavathi KG. Antiulcer effect of amlodipine and its interaction with $\mathrm{H} 2$ blocker and proton pump inhibitor in pylorus legated rats. Indian Journal of Pharmacology 2006; 38:403-7.

3. Khalil J, Akhter S, Bhatti SA, Bukhari MH. Gastric ulcer healing effects of Nigella Sativa; a comparative experimental study with Cimetidine. Biomedica 2010; 26:61-5.

4. Hunt RH, Xiao SD, Megraud F, et al. Helicobacter pylori in developing countries. World Gastroenterology Organisation Global Guideline. J Gastrointestin Liver Dis 2011; 20:299-304.

5. Kudva MV, Thein-Htut. Profile of peptic ulcer disease in Malaysia. Singapore Med J 1988; 29: 544-7.

6. Kang JY. Some observations on the epidemiology of peptic ulcer disease in Singapore. Singapore Med J 1992; 33:468-71.

7. Sud R, Puri R. Medical management of peptic ulcer. In: Kohli K, Gupta M, Tejwani S, eds: Contemporary perspectives on clinical pharmacotherapeutics. Reed Elsevier India pvt. limited, 2006: 366-74.

8. Valle JD. Peptic ulcer disease and relative disorder. In: Braunwald E, Fauci AS, Kasper DL, Hauser SL, Longo DL, Jameson JL, eds: Arrison's principles of internal medicine. New York: McGraw-Hill, 2005: 1746-62.

9. Falcão HS, Mariath IR, Diniz MF, Batista LM, Barbosa-Filho JM. Plants of the American continent with antiulcer activity. Phytomedicine 2008;15:132-46.

10. Rao CV, Maiti RN, Goel RK. Effect of mild irritant on gastric mucosal offensive and defensive factors. Indian J Physiol Pharmacol 2000; 44:18591.

11. Manso CF. Alcohol and free radicals. Various consequences: protein synthesis, endocrine disorders, immunity, role of stress. Acta Med Port 1997; 10:809-17.

12. Rang HP, Dale MM, Ritter M, et al., eds.

Pharmacology, 5th edition. Edinburgh: ChurchillLivingstones, 2003.

13. Reshma, S, Vijay Kumar K, Naidu MUR, Ratnakar KS. Effects of Gingko biloba extract on ethanolinduced gastric mucosal lesions in rats. Indian Journal of Pharmacology 2000; 32:313-17.

14. Ko JKS, Cho $\mathrm{CH}$, Ogle CW. The vagus nerve and its non-cholinergic mechanism in the modulation of ethanol induced gastric mucosal damage in rats. J Pharm Pharmacol 1994; 46:29-33.

15. Rates SMK. Plants as source of drugs. Toxicon 2001;39:603-13.

16. Kakei N, Ichinose M, Tsukada S, et al. Omeprazole, a proton pump inhibitor, reduces the secretion, synthesis and gene expression of pepsinogen in the rat stomach. Biochem Biophys Res Commun 1993; 195:997-1004.

17. Howden CW, Hunt RH. Peptic ulcer disease. In: Lewis JH, eds. A pharmacologic approach to gastrointestinal disorders. Maryland: Williams and Wilkins, 1994: 1-21.

18. Rama Devi M, Subramanian NS, Gupta VRM, Giri Prasad BS, Reddy CM. Anti gastric ulcer activity of Plectranthus amboinicus (Lour) in wistar albino rats. J Chem Pharm Res 2010; 2: 374-380.

19. Farnsworth NR, Akerele O, Bingel AS, Soejarto DD, Guo Z. Medicinal plants in therapy. Bull World Health Organ 1985; 63:965-81.

20. Misiewicz JJ, Pounder RE. Peptic ulcer. In: Weatherall DJ, Ledingham JGG, Warrel DA, eds. Oxford Textbook of Medicine (4th Ed). New York: Oxford university press 1988; 64-76.

21. Mahmood AA, Al-Bayaty FH, Salmah I, et al. Enhancement of gastric ulcer by Areca catechu nut in ethanol-induced gastric mucosal injuries in rats. Journal of Medicinal Plants Research 2011;5:2562-9.

22. Al-Rifai AS. A study on the pathogenesis of induced peptic ulcer and its therapy. Unpublished Ph.D. thesis, Baghdad University, Baghdad, Iraq. 1995.

23. Abdulla MA, Ahmed KAA, AL-Bayaty, FH, Masood Y. Gastroprotective effect of Phyllanthus niruri leaf extract against ethanol-induced gastric mucosal injury in rats. African Journal of Pharmacy and Pharmacology 2010; 4:226-30.

24. Szabo S, Trier, JS, Brown A, Schnoor J. Early vascular injury and increased vascular permeability in gastric mucosal injury caused by ethanol in the rat. Gastroenterology 1985; 88:228-36.

25. Ritchie JM. The aliphatic alcohols. In: Gilman AG, Goodman LS, Rall TW, Murad F, eds. The pharmacological basis of therapeutics (7th Ed). New York: MacMillan Publishing Company, 1985: 372-386.

26. Harvey SC. Gastric antacids, Miscellaneous drugs for treatment of peptic ulcer, digestants and bile acids. In: Gilman AG, Goodman LS Rall TW Murad 
F, eds. The Pharmacological basis of Therapeutics (7th ed). New York: MacMillan Publishing Company, 1985; 980-93.

27. Bensky D, Clavey S, Erich Stoger, et al. Chinese Herbal Medicine: Materia Medica. 3rd ed. Seattle, WA: Eastland Press, 1993.

28. Galati EM, Pergolizzi S, Miceli N, Monforte MT, Tripodo MM. Study on the increment of the production of gastric mucus in rats treated with puntiaficusindica (L.) Mill. cladodes. J Ethnopharmacol 2002; 83:229-33.

29. Khazaei M, Salehi H. Protective effect of Falcaria vulgaris extract on ethanol induced gastric ulcer in rat. Iranian Journal of Pharmacology and Therapeutics 2006; 5:43-6.

30. Dharmani P, Kumar KV, Srivastava S, Palit G. Ulcer healing effect of anti-ulcer agents: A comparative study. The Internet Journal of Academic Physician Assistants 2003; 3. DOI: 10.5580/11e2. Available at: http://archive. ispub.com/journal/the-internet-journal-ofacademic-physician-assistants/volume-3number-2/ulcer-healing-effect-of-anti-ulceragents-a-comparative-study.html\#sthash. Q43SRceK.dpbs. Accessed February 2012.

31. Nakamura M, Akiba Y, Oda M, Ishii H. Appearance of myofibroblasts in the gastric mucosa after ingestion of ethanol and lansoprazole with revaluation of the mucoid cap. Alcohol Clin Exp Res 1998; 22:115s-20s.

32. Wallace JL. Nonsteroidal anti-inflammatory drugs and the gastrointestinal tract. Mechanisms of protection and healing: current knowledge and future research. Am J Med 2001; 110:19S235.

33. Das S, Deka S, Gohain K. A preclinical study on the gastric ulcer protective activity of the world's hottest chilli, Capsicum frutescence. J Clin Dia Res 2008; 2:1024-7.

34. Coșkun O, Kanter M, Armutçu F, et al. Protective effects of Quercetin, a Flavonoid antioxidant, in absolute ethanol-induced acut gastric ulcer. European Journal of General Medicine 2004; 1:37-42.

35. Darbar S. Antiulcer effect of Livina, a herbal formulation against ethanol induced acute gastric ulcer in mice. International Journal of Pharmaceutical Research (Online) 2010; 2:93100.

36. Chaturvedi A, Kumar MM, Bhawani G, et al. Effect of ethanolic extract of Eugenia jambolana seeds on gastric ulceration and secretion in rats. Indian Journal of physiology and Pharmacology 2007; 51:131-40.

37. Ligha $A E$, Fawehinmi HB. Protection by liquorice in alcohol induced gastric mucosa damage.

Pakistan Journal of Nutrition 2009; 8:1532-6. 